\title{
Improving stroke patients' care: a patient held record is not enough Mulunish Ayana ${ }^{1}$, Pandora Pound ${ }^{2}$, Fiona Lampe ${ }^{1}$ and Shah Ebrahim*3
}

\author{
Address: ${ }^{1}$ Department of Primary Care \& population Sciences, Royal Free Hospital School of Medicine, Rowland Hill Street, London NW3 2PF, \\ ${ }^{2}$ Department of Public Health Sciences, Guy's King's \& St Thomas' School of Medicine and ${ }^{3}$ Department of Social Medicine, Univeristy of Bristol \\ E-mail: Mulunish Ayana - mea4a@clinmed.gla.ac.uk; Pandora Pound - p.pound@umds.ac.uk; Fiona Lampe - f.lampe@rfhsm.ac.uk; \\ Shah Ebrahim* - shah.ebrahim@bristol.ac.uk \\ ${ }^{*}$ Corresponding author
}

Published: 6 March 200I

BMC Health Services Research 200I, I:I

This article is available from: http://www.biomedcentral.com/1472-6963/I/I

(c) 200 I Ayana et al, licensee BioMed Central Ltd.
Received: 18 January 2001

Accepted: 6 March 2001

\begin{abstract}
Background: Stroke patients' care in hospital tends to be poorly organised, with poor communication and a lack of information being frequent sources of complaint. The purpose of this study was to evaluate whether a patient-held record (PHR) would result in greater patient satisfaction and better care planning for stroke patients.
\end{abstract}

Methods: A time series control (6 months) - intervention (8 months) - control (6 months) was used among London teaching hospital general medical and geriatric medicine inpatient wards. All stroke patients admitted to the wards during the intervention phase received a PHR and were instructed in its use. Demographic, stroke severity, social factors and outcomes were collected from all stroke patients during all phases of the study.

Results: Of 252 stroke patients aged 46 to 98 years entered into the study, by six months after admission II 8 (46.8\%) had died. PHR and control group patients were well matched in terms of socio-demographic characteristics and pre-stroke ability. At six months after admission, 119 (97\%) patients responded to the questionnaire. Just over half $(56 \%, 13)$ of intervention group patients recalled receiving a PHR. Of those patients, 59\% reported reading the PHR, 27\% had lost their PHR, and two-thirds said they had difficulties encouraging staff to write in the PHR. Half felt that possession of the PHR was more trouble than it was worth. PHR group patients were more satisfied with the recovery they had made $(79 \% \mathrm{vs.} 59 \%, p=0.04)$, but felt less able to talk to staff about their problems $(61 \%$ vs. $82 \%, p=0.02)$. PHR group patients reported receiving fewer explanations about their condition ( $18 \%$ vs. $33 \%, p=0.12)$ and treatment $(26 \%$ vs. $45 \%, p=0.07)$, and were more afraid of asking doctors questions $(21 \%$ vs. $4 \%, p=0.01)$ than controls. PHR group patients were no better prepared for hospital discharge than control group patients, and both groups were ill-informed about services and benefits that might have helped after discharge from hospital.

Conclusions: Stroke patients received poor information and explanations regardless of whether they received a PHR. A PHR did not appear to improve patient satisfaction or discharge planning, and may have reduced opportunities for communication and explanation. 


\section{Introduction}

Poor communication and lack of information are among the most common complaints of people with stroke $[1,2,3]$. Stroke services are poorly organised in many countries with a lack of continuity of care between hospital and community [4]. Consequently it is not surprising that dissatisfaction with services, especially those received after discharge, is common [5]. Patient held records (PHRs) exist in a variety of formats $[6,7]$ and have been used in many different settings $[8,9,10]$. Individualised information booklets have been used with stroke patients before [11], but do not provide a continued record of care, their sole role being to provide information. In other areas of health care, patients are enthusiastic about holding their own records since they allow access to information, increase autonomy and bring about a shared feeling of responsibility for health $[12,13,14]$. PHRs have not been evaluated for use with stroke patients before.

A PHR might benefit stroke patients by providing information, promoting a more active role in their care and the possibility of contributing to decision making. As many people are involved in the care of stroke patients, possession of a PHR might give patients the confidence to ask questions of staff and they might receive more explanation. A PHR used by all members of the rehabilitation team, both in and out of hospital, could improve communication between team members. Consequently, our main hypothesis was that stroke patients with a PHR would be more satisfied with their care and would receive better planned care than those without a PHR.

\section{Methods}

A controlled comparison study with a control-intervention-control (A1-B-A2) time series design was used. Phase A1 was an initial six month control period, phase B was an eight month intervention with use of the PHR for all stroke patients, and phase A2 was the six-month period immediately after withdrawal of distribution of the PHR. Stroke patients admitted during phase A1 and A2 were combined and used as control patients for comparison with those admitted during phase B. This time-series design was used as a randomised controlled comparison of individual patients would not have been feasible within a single hospital because of contamination of the control group. A contemporary comparison with another hospital would not have provided any control over the amount or type of therapy and care received. Cluster randomisation of several hospitals would have been possible but would have increased the costs of an exploratory study to an unreasonable level.
Our study was planned to have a target sample size of 75 patients in the PHR group and 150 in the control group which would have given $80 \%$ power to detect a difference of $20 \%$ between PHR and control groups in specific areas of patient satisfaction. Stroke admission rates were lower during the PHR phase, so this was extended.

The patient held record was an A5 (metric) pocket-sized booklet with a hard cover and the patient's name on the front. The telephone numbers of all relevant staff were included and space was provided for assessment and management decisions to be recorded. Patients could also record their own comments. The PHR did not replace the existing case notes kept by each professional group. Therapists were asked to write in the PHR every time they saw a patient but nurses and doctors who had multiple daily contacts with patients were not expected to do this. Therapists were asked to record details of each of the main needs or problems they dealt with and then to outline any action taken and any immediate or longer term outcome, as previously reported [15].

Preparatory meetings were held with groups of staff to discuss their views on the value, design and content of the PHR. Prior to introduction of the PHR, interviews were held with therapists to explore their views on the use of the PHR [15]. Letters were sent to all medical and other staff who had contact with stroke patients informing them of the aims of the study and how the PHR should be used. The PHR was explained verbally to groups of nurses on each of the wards and repeated whenever it was felt necessary by the researchers.

Patients were given the PHR by a researcher (MA) who obtained informed consent to take part in the study and were encouraged to ask their therapists to write in the PHR and were asked to take the PHR home and use it with any health or social services staff they were in contact with after discharge. In cases where patients were too cognitively impaired to use the PHR themselves, these tasks were entrusted to a carer. If patients were too ill in the initial stages of their admission or without carers, the use of the PHR was delayed until patients were better able to understand. The PHRs were collected at six months after stroke or at death.

Patients admitted with new or recurrent strokes defined using clinical criteria (i.e. acute focal or global neurological disturbance of presumed vascular origin) were recruited via twice weekly visits to each acute admitting general medical and geriatric medicine ward in the hospital. Demographic data and pre-stroke levels of ability (Barthel activities of daily living index [16] and Nottingham extended activities of daily living index [17]) were recorded at initial assessment. All patients were followed 
up at six months following admission to hospital using postal questionnaires including a previously validated patient satisfaction questionnaire [3], the Barthel index and questions about information received on diagnosis, prognosis, treatment and rehabilitation, their involvement in treatment and plans for discharge from hospital, attitudes to recovery and their opinions of the PHR.

Analyses were carried out using SPSS. Categorical variables were compared between groups using chi-square tests or Fisher's exact test for expected counts less than 5. Logistic regression analysis was used to adjust comparisons between groups for other baseline variables. The study was approved by the Royal Free Hospital Local Ethics Committee.

\section{Results}

During the twenty months of the study, 252 stroke patients were entered into the study, with 87 in the intervention phase $B$ and the remaining 165 in the two control phases A1 and A2. At six-months following admission, 118 (47\%) had died with $40 \%$ in phase B and 51\% in the control phases $(\mathrm{p}=0.20)$, and 11 were lost to follow up (nine could not be traced and two had left the country).
Therefore, 123 survivors received questionnaires at six months of whom 119 (97\%) responded. Complete data were available on Barthel index but patient satisfaction data was less complete owing to difficulties in patients with specific cognitive impairments or confusion who could not answer these questions.

The PHR and control groups were comparable in sociodemographic characteristics as shown in Table 1. The majority of patients had suffered their first stroke but just over half had some problems with basic activities of daily living pre-stroke as shown by their Barthel scores. At six months, functional ability was similar in both groups.

\section{Use of the PHR}

Although all patients in phase B received the PHR, only $56 \%$ (22 out of 39) reported they had ever had one. Of these, nine reported that they had not read their PHR, six had lost it, 14 had had difficulties persuading staff to write in it, and only six felt that the PHR had kept them informed about their treatment. Eleven of the patients thought that the PHR was more trouble than it was worth.

Table I: Baseline Characteristics in Phase A (control) and Phase B (patient held record)

\begin{tabular}{|c|c|c|c|}
\hline & Phase A & Phase B & P-value $^{+}$ \\
\hline Total number of subjects $\mathrm{N}$ & 165 & 87 & - \\
\hline Mean age (range) & $78(53-93)$ & $79(46-98)$ & $0.62^{*}$ \\
\hline \multicolumn{4}{|l|}{$\operatorname{Sex} n(\%)$} \\
\hline Male & $61(37.0)$ & $38(43.7)$ & \\
\hline Female & $104(63.0)$ & $49(56.3)$ & 0.30 \\
\hline \multicolumn{4}{|l|}{ Race n (\%) } \\
\hline White & $15 \mid(9 \mid .5)$ & $72(82.8)$ & \\
\hline Non-white & $14(8.5)$ & $15(17.2)$ & 0.04 \\
\hline \multicolumn{4}{|l|}{ Living conditions n (\%) } \\
\hline Alone & $79(47.9)$ & $33(37.9)$ & \\
\hline Not alone/institutionalised & $86(52.1)$ & $54(62.1)$ & 0.13 \\
\hline \multicolumn{4}{|l|}{ Last employment n (\%) } \\
\hline Manual & $73(58.9)$ & $4 I .(52.6)$ & \\
\hline Non-manual & $5 I(4 I . I)$ & $37(47.4)$ & 0.38 \\
\hline \multicolumn{4}{|l|}{ Pre-stroke Barthel n (\%) } \\
\hline 0.14 & $31(18.8)$ & $16(18.4)$ & \\
\hline $15-19$ & $55(33.3)$ & $30(34.5)$ & \\
\hline 20 & 79 47.9) & $41(47.1)$ & 0.98 \\
\hline \multicolumn{4}{|c|}{ Pre-stroke extended ADL n (\%) } \\
\hline$<6$ & $58(35.2)$ & $32(36.8)$ & \\
\hline $6-17$ & $54(32.7)$ & $29(33.3)$ & \\
\hline $18-22$ & $53(32.1)$ & $26(29.9)$ & 0.93 \\
\hline \multicolumn{4}{|l|}{ Ward on admission $\mathrm{n}(\%)$} \\
\hline General medical & $56(33.9)$ & $43(49.4)$ & \\
\hline Geriatric & $109(66.1)$ & $44(50.6)$ & 0.02 \\
\hline
\end{tabular}

${ }^{+}$Chi-squared or Fisher's Exact Test ${ }^{*}$ T-test 


\section{Patient satisfaction}

There were few differences in satisfaction between PHR and control groups (see Table 2). PHR group patients were happier with the recovery they had made (79\% vs. $59 \%, p=0.04$ ) but they were significantly less satisfied that they could talk to staff about problems (61\% vs. $82 \%$, $\mathrm{p}=0.02)$. Both groups reported high levels of disatisfaction with community services received. Adjustment for age, sex, race, admission ward and disability at six months in a logistic regression on patient satisfaction questions made little difference to the odds ratios of satisfaction associated with the PHR.

\section{Information recalled}

More control than PHR group patients reported that someone had explained about the chances of recovery, the effects of stroke on their lives, the reasons of investigations and the findings (see Table 3). Patients in both groups reported wanting more information from doctors than from any other professional group.

\section{Involvement}

Most patients (68\% PHR vs. 61\% control, $\mathrm{p}=0.39$ ) were not involved in discussions about their treatment with doctors or therapists. Slightly more (61\%) PHR group patients than control patients (49\%) reported that they had had little idea what was happening to them while they were in hospital. The vast majority of patients in both groups felt able to ask questions of therapists and social workers. However, PHR group patients were significantly more afraid to ask questions of doctors than control group patients ( $21 \%$ vs. $4 \%, \mathrm{p}=0.01$ ).

Table 2: Differences in patient satisfaction in Phase A (control) and Phase B (patient held record)

\begin{tabular}{|c|c|c|c|c|c|c|c|}
\hline & $\begin{array}{l}\text { Phase A } \\
\mathrm{N}\end{array}$ & Satisfied n (\%) & $\begin{array}{l}\text { Phase B } \\
\mathrm{N}\end{array}$ & Satisfied n (\%) & P-value & $\begin{array}{l}\text { Differences in } \\
\% 2 \\
\text { B-A }(95 \% \mathrm{Cl})\end{array}$ & $\begin{array}{l}\text { Adjusted } \\
\text { odds ratios } \\
(95 \% \mathrm{Cl}) \S\end{array}$ \\
\hline \multicolumn{8}{|l|}{ Hospital Care } \\
\hline Treated with kindness & 57 & $53(93.0)$ & 38 & $34(89.5)$ & $0.71^{*}$ & $-3.5(-15.3,8.3)$ & $0.6(0.1,3.2)$ \\
\hline Staff attended to needs & 57 & $47(82.5)$ & 37 & $31(83.8)$ & 0.87 & I.3 (-14.1, I6.8) & I.I $(0.3,3.4)$ \\
\hline Able to talk about problems & 56 & $46(82.1)$ & 38 & $23(60.5)$ & 0.02 & $-21.6(-40.1,-3.1)$ & $0.3(0.1,0.9)$ \\
\hline Given information re illness & 58 & $39(67.2)$ & 38 & $20(52.6)$ & 0.15 & $-14.6(-34.6,5.3)$ & $0.5(0.2,1.1)$ \\
\hline Doctors done all they can & 57 & $49(86.0)$ & 38 & $35(92.1)$ & $0.52^{*}$ & $6.1(-6.3,18.6)$ & $2.0(0.5,8.5)$ \\
\hline Happy with recovery & 58 & $34(58.6)$ & 38 & $30(78.9)$ & 0.04 & $20.3(2.2,38.5)$ & $2.9(1.1,8.5)$ \\
\hline Satisfied with type of therapy & 52 & $46(88.5)$ & 31 & $28(90.3)$ & $1.00^{*}$ & $1.9(-11.7, \mid 5.4)$ & I.5 $(0.3,7.1)$ \\
\hline I have had enough therapy & 56 & $31(54.4)$ & 35 & $24(68.8)$ & 0.21 & $13.2(-6.9,33.4)$ & $1.9(0.7,5.0)$ \\
\hline \multicolumn{8}{|l|}{ Home Care } \\
\hline $\begin{array}{l}\text { Satisfied with amount of contact } \\
\text { with hospital }\end{array}$ & 46 & $38(82.6)$ & 28 & $22(78.6)$ & 0.67 & $-4.0(-22.8,14.7)$ & $0.7(0.2,3.0)$ \\
\hline $\begin{array}{l}\text { Information wanted about allow- } \\
\text { ances/benefits }\end{array}$ & 46 & $28(60.9)$ & 23 & 17 (73.9) & 0.28 & $13.0(-9.9,35.9)$ & $2.0(0.6,7.1)$ \\
\hline $\begin{array}{l}\text { Good preparation for return } \\
\text { home }\end{array}$ & 42 & $39(92.9)$ & 21 & $20(95.2)$ & $1.00^{*}$ & $2.4(-9.6,14.4)$ & $-t$ \\
\hline Satisfied with service & 58 & $17(29.3)$ & 39 & $10(25.6)$ & 0.69 & $-3.7(-2|.7| 4.4)$, & $0.8(0.3,2.2)$ \\
\hline
\end{tabular}

* Fisher's Exact Test (Two-Tail), §adjusted for age, sex, race, admission ward, disability at 6 months, $†$ not estimatable

\section{Discharge planning}

Almost three-quarters of patients in both groups were given adequate notice of when they would be going home. More PHR than control group patients felt ready to go home at the point of discharge ( $82 \%$ vs. $60 \%$, $\mathrm{p}=0.14$ ), but control group patients were more likely to have been instructed in how to cope at home (49\% vs. $33 \%, \mathrm{p}=0.11$ ). Just over a third of patients had been told about services at home that might be helpful, and only a quarter had had welfare benefits explained to them.

\section{Recovery}

Significantly more PHR than control group patients felt that they had made a complete recovery from the stroke (38\% vs. 14\%, $\mathrm{p}=0.01$ ), and a higher proportion felt that they had "got their lives back together again" (48\% VS. $31 \%, \mathrm{P}=0.08)$. Despite this, two-thirds of patients in both groups needed help with everyday activities. Both groups reported a positive outlook, attributing recovery to their own efforts and determination, and had not lost hope. 
Table 3: Comparison of information received by patients in phase A (control) and phase B (patient held record)

\begin{tabular}{|c|c|c|c|c|c|c|}
\hline & Phase A & & Phase B & & P-value & Differences in \%s \\
\hline & $\mathrm{N}$ & Yes n (\%) & $\mathrm{N}$ & Yes n (\%) & & B-A $(95 \% \mathrm{Cl})$ \\
\hline \multicolumn{7}{|l|}{ Someone explained to me about: } \\
\hline The causes of my stroke & 58 & $21(36.2)$ & 38 & $12(31.6)$ & 0.64 & $-4.6(-23.9,14.6)$ \\
\hline My chances of recovery & 58 & $31(53.4)$ & 38 & $13(34.2)$ & 0.06 & $-19.2(-39.0,0.6)$ \\
\hline The possible effects of the stroke on my life & 58 & $19(32.8)$ & 38 & $7(18.4)$ & 0.12 & $-14.3(-3 \mid .6,2.9)$ \\
\hline The reasons for the tests I had & 58 & $26(44.8)$ & 38 & $10(26.3)$ & 0.07 & $-18.5(-37.5,0.5)$ \\
\hline The results of the tests I had & 58 & $23(39.7)$ & 38 & $9(23.7)$ & 0.10 & $-16.0(-34.4,2.5)$ \\
\hline How being treated in hospital might help & 58 & $20(34.5)$ & 38 & $6(15.8)$ & 0.04 & $-18.7(-35.5,-1.8)$ \\
\hline \multicolumn{7}{|l|}{ Someone explained to me about: } \\
\hline The reasons for needing physiotherapy & 48 & $36(75.0)$ & 28 & $19(67.9)$ & 0.51 & $-7.1(28.3,14.1)$ \\
\hline Exercises to do on my own & 50 & $36(72.0)$ & 27 & $20(74.1)$ & 0.84 & $2.1(118.6,22.8)$ \\
\hline The use of aids (eg stick) & 39 & $31(79.5)$ & 20 & $16(80.0)$ & 0.96 & $5.1(-21.1,22.1)$ \\
\hline The reason for needing occupational therapy & 47 & $30(63.8)$ & 25 & $13(52.0)$ & 0.33 & $-11.8(-35.8,12.1)$ \\
\hline The use of aids (in eg your kitchen/bathroom) & 45 & $23(7 \mathrm{I} . \mathrm{I})$ & 23 & $18(78.3)$ & 0.53 & $7.1(14.3,28.6)$ \\
\hline The reasons for need speech therapy & 24 & $14(58.3)$ & 18 & II (6I.I) & 0.86 & $2.8(-27.2,23.7)$ \\
\hline The use of communication aids & 21 & $12(57.1)$ & 17 & $7(4 \mid .2)$ & 0.33 & $-16.0(-47.5,15.6)$ \\
\hline \multicolumn{7}{|l|}{ Would have liked more information from: } \\
\hline Doctors & 57 & $23(40.4)$ & 39 & $15(38.5)$ & 0.85 & $-1.9(-21.8,18.0)$ \\
\hline Nurses & 57 & $13(22.8)$ & 39 & II (28.2) & 0.55 & $5.4(-12.4,23.2)$ \\
\hline Physiotherapists & 48 & $12(25.0)$ & 28 & $10(35.7)$ & 0.32 & $10.7(-10.9,32.3)$ \\
\hline Occupational therapists & 43 & $8(18.6)$ & 26 & $10(38.5)$ & 0.07 & $19.9(-2.2,41.9)$ \\
\hline Speech therapists & 26 & $6(23.1)$ & 19 & $5(26.3)$ & 0.80 & $3.2(22.3,28.8)$ \\
\hline Social workers & 30 & $10(33.3)$ & 21 & $5(23.8)$ & 0.46 & $-9,5(-34.4,15.3)$ \\
\hline
\end{tabular}

\section{Discussion}

This is the first evaluation of a PHR, an intervention that has worked reasonably well in other clinical circumstances. Our hypothesis that the PHR would increase patient satisfaction is not supported by our findings. It is possible that the time series design was responsible for these disappointing findings. Non-randomised comparisons run the risk of introducing selection bias and fail to control for other potentially confounding factors that may bias assessment of outcomes. In this case, while our patient case mix was similar at baseline, the mortality rate was a little lower in the PHR intervention phase and more people were admitted to general medical wards. However, adjustment for age, sex, race, admission ward and Barthel index did not materially alter out findings. The inclusion of a second control phase following withdrawal of the intervention strengthens a time series design and permits any non-specific effects not associated with intervention to be evaluated. As with any non-randomised comparison, our findings must be viewed with some caution.

There are several possible explanations for our negative findings. As death rates were higher than anticipated, our effective sample size for most comparisons was re- duced but was still sufficiently powerful to detect clinically important differences of about 30\% in satisfaction. It is possible that PHRs were given to patients who were simply too sick to use them, but we attempted to enter all available patients into the study to assess the usefulness of the PHR for all stroke patients. Our findings tended to show that, if anything, patients who received a PHR did rather worse for most outcomes than those who did not. Why should this be? Disinterest, as has been found elsewhere [18], may be a reason why so many patients did not know they had a PHR or did not bother to read it. Some difficulties in its use may be attributed to the high turnover of staff and routine rotation of therapists, but most therapy staff had been involved in the design and inception of the PHR and certainly wanted it to work. Although all of the medical consultants managing stroke patients agreed for their patients to be studied, none of them acted as "champions" for the innovation. This lack of medical involvement may have contributed to the disappointing findings and limited use of the PHR.

That patients would lose their PHR was anticipated by therapists at the start of the study [15], and reflects the negative views of patients' ability among health professionals $[8,12,13,18]$. Women who hold their antenatal 
records rarely lose them $[7,12,19]$, but pregnant women are not ill. We wanted to challenge the expectation that older, disabled patients would be unable to take responsibility by evaluating the PHR among patients who generally lack power [20]. But perhaps these patients were simply too ill - as suggested by the high mortality rate - to make use of a PHR.

Our findings contrast with those which suggest that patients with a PHR experience less difficulty talking to staff and feel empowered [10,21]. It is possible that in the PHR group communication problems were caused by the PHR. It may have hightened their expectations and hopes which do not appear to have been fully met. Discussing a poor prognosis is an extremely difficult task for health professionals [22]. Making written entries in a PHR may have increased this difficulty as it is easier to be vague verbally than in writing [15] and this may have deterred staff from writing in the PHR.

\section{Conclusion}

We expected the PHR to bridge the gap between hospital and the community, contributing to the continuity of care that has been found elsewhere [10]. This did not occur and our findings highlight the generally high levels of disatisfaction with services received after leaving hospital. Introducing a PHR into stroke care, an area of health care recognised to be hapazard and fragmented [5], was an ambitious undertaking. Changing the well-established culture and practice of stroke patient care will take more powerful interventions than a PHR. PHRs have been shown to be effective in some clinical settings but such findings are not applicable to the the more difficult circumstances of the acute hospital care of frail and often confused patients. This study has drawn attention to the generally poor levels of information and explanation given to patients and their lack of involvement in their care, regardless of whether they had a PHR.

\section{Acknowledgements}

We would like to thank the patients and their carers for contributing to the research. Mulunish Ayana was funded by the North Thames NHS Executive Research \& Development programme. Pandora Pound was funded by the Stroke Association.

The Department of Social Medicine of the University of Bristol is the lead centre of the MRC Health Services Research Collaboration.

\section{References}

I. Wellwood I, Dennis MS, Warlow CP: Perceptions and knowledge of stroke among surviving patients with stroke and their carers. Age Ageing 1994, 23:293-8

2. Drummond $A$, Lincoln $N$, Juby $L$ : Effects of a stroke unit on knowledge of stroke and experience in hospital. Health Trends 1996, 28:26-30

3. Hanger HC, Mulley GP: Questions people asked about stroke. Stroke 1993, 24:536-8

4. King's Fund Consensus Statement Treatment of stroke. BMJ 1993, 297:126-128
5. Pound $P$, Gompertz $P$, Ebrahim S: Patient's satisfaction with stroke services. Clin Rehab. 1994, 8:7-17

6. Liaw T, Laurence $M$, Rendell J: The effect of a computer-generated patient-held medical record summary and/or a written personal record on patients' attitudes, knowledge and behaviour concerning health promotion. Family Practice 1996, I 3:289-293

7. Aikin P, Finnigan P, Ogle SJ, Shenfield GM: Are medication records cards useful? Medical Journal of Australia 1996, I62:300-I

8. Lovell A, Zander LI, James CE, Foot S, Swan AV, Reynolds A: The St Thomas's Maternity Case Notes study: a randomised controlled trial to assess the effects of giving expectant mothers their maternity case notes. Paedtr Perinat Epidemiol 1987, I:57-66

9. Saffin K, MacFarlane A: How well are patient-held records kept and completed? Br J Gen Pract I991, 41:249-5 I

10. Essex B, Doig R, Renshaw J: Pilot study of records of shared care for people with mental illnesses. BM] 1990, 300: |442-6

II. Pain HSB, McLellan DL: The use of individualised booklets after stroke. Clinical Rehabilitation 1990, 4:265-72

12. Elbourne D, Richardson M, Chalmers I, Waterhouse I, Holt E: The Newbury Maternity Care Study: a randomised controlled trial to evaluate a policy of women holding their own obstetric records. $\mathrm{Br}$ J Obs Gyn 1987, 94:6I2-19

13. Sheldon MG: Giving patients a copy of their computer medical record. J Roy Coll Gen Pract 1982, 32:80-60

14. Metcalfe DHH: Why not let patients keep their own records? J Roy Coll Gen Pract 1980, 30:420-

15. Ayana ME, Pound P, Ebrahim S: The views of therapists on the use of a patient-held record in the care of stroke patients. Clinical Rehabilitation 1998, I 2:328-337

16. Collin C., Wade DT, Davies S, Horne V: The Barthel ADL Index: a reliability study. International Disability Studies 1988, 10:6 I-63

17. Nouri FM, Lincoln NB: An extended activities of daily living index for stroke patients. Clin Rehab. 1987, I:301-3

18. Norwich Community Health Partnership Clinical Audit Department. Client Held Records at Kelling Hospital. 1995,

19. Reid M, Garcia J: Womens views of caring during pregnancy and childbirth, in Effective Care in Pregnancy and Childbirth, Chalmers I, Enking M, Keirse M (eds.) Oxford, OUP 1989,

20. Seale C: The consumer voice, in Dilemmas in Health Care, Davey $B$, Popay J (eds.) Oxford, OUP 1993,

21. Webster J, Forbes K, Foster S, Thomas I, Griffin A, Timms H: Sharing Antenatal Care: Client satisfaction and use of the 'Patient-held Record'. Aust. NZ J Obstet Gynaecol 1996, 36: I I-I 5

22. Pound $P$, Bury M, Gompertz P, Ebrahim S: Views of survivors of stroke on benefits of physiotherapy. Qual Health Care 1994, 3:6974

\section{Pre-publication history}

The pre-publication history for this paper can be accessed here:

http://www.biomedcentral.com/content/backmatter/ 1472-6963-1-1-b1.pdf

Publish with BioMedcentral and every scientist can read your work free of charge

"BioMedcentral will be the most significant development for disseminating the results of biomedical research in our lifetime." Paul Nurse, Director-General, Imperial Cancer Research Fund

Publish with BMc and your research papers will be:

- available free of charge to the entire biomedical community

- peer reviewed and published immediately upon acceptance

- cited in PubMed and archived on PubMed Central

- yours - you keep the copyright

Submit your manuscript here: http://www.biomedcentral.com/manuscript/ 